\title{
An ontology of systematic relations for a shared grammar of Slavic
}

\author{
Tania AVGUSTINOVA \\ Computational Linguistics, Saarland University \\ P. O. Box 151150 \\ Saarbrücken, Gcrmany, D-66041 \\ avgustinova@coli.uni-sb.de
}

\author{
Hans USZKOREIT \\ Language Technology Lab, DFKI \\ Computational Linguistics, Saarland University \\ Saarbrïcken, Germany, D-66041 \\ uszkorcit@dfki.de
}

\begin{abstract}
Sharing portions of gramunars across languages greatly redaces the costs of multilingual grammar engineering. Related languages share a much wider range of linguistic information than typically assumed in standard multilingatal gramumar architectures. Taking grammatical relatedness seriously, we are particularly interested in designing linguistically motivated grammatical resoumes for Slavic languages to be used in applied and theoretical computational linguistics. In order to gain the perspective of a language-family oriented granmar design, we consider an array of systematic relations that cam hold between syntactical units. While the categorisation of primitive linguistic entities tends to be language-specific or even construction-specific, the relations holding between then allow various degrees of abstraction. On the basis of Slavic data, we show how a domain ontology conceptaalising morphosyntactic "building blocks" can serve as a basis of a shared grammatr of Slavic.
\end{abstract}

\section{Introduction}

In applied computational linguistics, the need for developing and utilising operational notions of shared grammars stems from multilingual grammar enginecring. If considerable portions of existing grammars can be reused for the specification of new grammars, development efforts can be greatly reduced. A shared grammar also facilitates the difficult task of maintaining consistency within and across the individual parallel grammars. In machine translation, the specification of a shared grammar can furthermore be exploited for simplifying the transfer process.

Without much ado, computational linguists engaged in multilingual grammar development have always tried to reduce their labour by importing existing grammar components in a simple "copy-pastemodify" fashion. But there were also a number of systematic attempts to create and describe shared grammars that are convincingly documented in publications. [Kam88] demonstrates the concept for a relatively restricted domain, the grammatical description of simple nominal expressions in five languages. [BOP88] were able to exploit the grammatical overlap of two Slavic languages, for the design of a lean transfer process in Russian to Czech machine translation. In multilingual application development within Microsoft research, grammar sharing has extensively been exploited [Pin96], [GLPR97].

However, all these approaches are rather opportunistic in the sense that existing grammatical descriptions based on existing grammar models were explored. We went a step further and started grammar design with a notion of a shared grammar for a family of related languages. Pursuing the goal of designing linguistically motivated grammatical resources for Slavic languages to be used in computational linguistics, one is inevitably confronted with primary problems stemming from the fact that different linguistic theories cut up grammars in quite different ways, and grammar formalisms differ in their degree of granularity. It cannot be expected, therefore, that the minimal differences between two languages or their shared elements form easily identifiable units in the available language-specific grammars. Therefore, an ontology conceptualising morphosyntactic "building blocks" would offer a solid basis for a shared grammar of Slavic in the sense of [ASU99]. Our use of the term ontology is fairly pragmatic, namely, as representing a formal shared conceptualisation of a particular domain of interest. It describes concepts relevant for the domain, their relationships, as well as "axioms" about these concepts and relationships. Note that such a pragmatic approach does not presuppose any general all-encompassing ontology of language but rather "mini-ontologies" conceptualising the selected domain from various perspectives in a consistent way. The domain of interest in this project is the grammatical knowledge on Slavic morphosyntax contained in linguistic theories and linguistic descriptions. While the categorisation of primitive linguistic entities tends to be language-specific or even construction-specific, the relations holding between them allow various degrees of abstraction. In order to gain the perspective of Janguage-family oriented grammar design, we will consider the array of systematic relations that can hold between syntactically significant items.

\section{Systematic relations}

Systematic relations motivate shared patterns of variation cross-linguistically as well as across constructions. In a constraint-based theory like HPSG, where the grammatical propertics of linguistic entities are typically revealed in complex taxonomies, nothing in the formal apparatus would actually exclude the possibility to organise also the relations holding in syntactic constructions in a type hierarchy. So, the type subsumption could be interpreted as modelling a continuum from general - and presumably universal - systematic relations to more and still more specific instances of these relations resulting from admissible cross-classifications.' In

\footnotetext{
1 The two types of edges connecting types in our graphical representation of hicrarchies - 'square' and 'direct' - arc significant. The former indicate possible conjunction of types, and thus introduce various dimensions of multiple inheritance. The latter indicate disjunction of types within the respective dimension of classification.
} 
our view, two orthogonal types of systematic relations have to be distinguished: syntagmatics and alignment, since they appear to be universally relevant for the well-formedness of utterances in any language (Hicrarchy 1$)^{2}$ Syntagmatic relations play a constitutive role in syntax by establishing instant connections between linguistic entities in various constructions. There is a covert, meaningful dimension of structural syntagmatics, and an overt, morphosyntactic, form-oriented dimension of combinatorial syntagmatics.

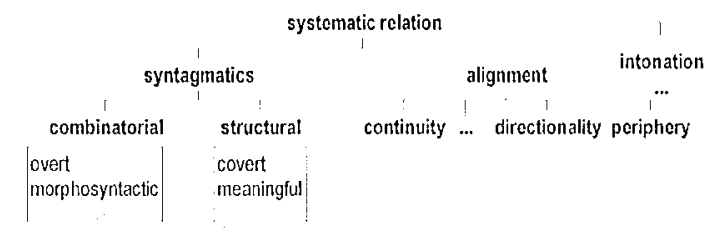

Hierarchy I: Systematic relations: dimensions of classification

With respect to the alignment relation, which is responsible for the actual lincar distribution of syntactically relevant itcms, we assume that at least the continuty of syntactic units, the directionality of the head (or, more generally, of a certain syntactically significant entity) as well as the periphery of a syntactically determined domain atre relevant dimensions of classification (Hicrarchy 2).

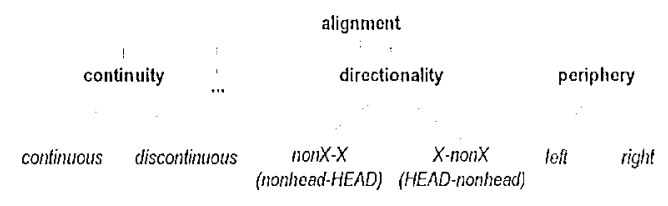

Hicrarchy 2: Alignnent

The continuity of syntactic units can be realised as immediate constituency (i.e. of type continuous) or as long-distance constituency (i.e. of type discontinuous). The directionality accounts for situations where, e.g., the head either follows the dependent or precedes it. In turn, the periphery of a syntactically determined domain can be left or right.

\section{Structural syntagmatics}

The structural syntagmatic relations between two syntactic units is classificd along two primary dimensions which we call centricity and taxis (Hierarchy 3). The chosen terms should be understood in the context of distinguishing, on the one hand, endocentric and exocentric relations, and on the other hand, hypotaxis and parataxis. The endocentricity of a structural syntagmatic relation (between, e.g., $\alpha$ and $\beta$ ) presupposes that one of the syntactic items involved in this relation (c.g., $\alpha$ ) plays a prominent role. In contrast, the exocentricity of a structural syntagmatic relation presupposes no assumptions in this respect, hence, it can be viewed as the unmarked member of the centricity opposition. The hypotaxis means that there is a depend-

\footnotetext{
2 The intonational organisation of utenanes by the way is another systematic relation exhibiting this trait. A more thorough investigation of the intonational aspect would be well beyond the morphosyntactic orientation of the present work.
}

ency of subordination between the involved syntactic items, while the parataxis is neutral in this respect and is regarded as the unmarked nember of the taxis opposition.

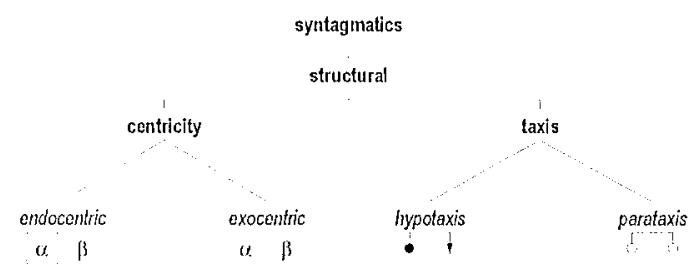

Hicrardy 3 : Centricity and laxis

Consequently, if two linguistic entities belong together from the viewpoint of structural syntagmaties, they are involved in one of the following relattion types which are obtained via admissible crossclassifications (Hicrarchy 4).

Endocentric hypotaxis, or selection. The headdependent configuration can be identified unambiguously. The prominent element is also the dominating one in the subordination.

Exocentric hypotaxis, or modification. There is no prominent element to unambiguously take over the role of a dominating item in the subordination. Note that this is where (theory-specific) linguistic conventions regarding the head-dependent configuration actually begin.

Endocentric parataxis. There is a prominent element in this relation, but no head-dependent configuration.

Exocentric parataxis. In the relation holding between the involved linguistic entities there is neither a prominent element nor a head-dependent configuration. This is the unmarked case with respect to both centricity and taxis.

$$
\begin{gathered}
\text { syntagmatics } \\
\text { structural }
\end{gathered}
$$

centricity
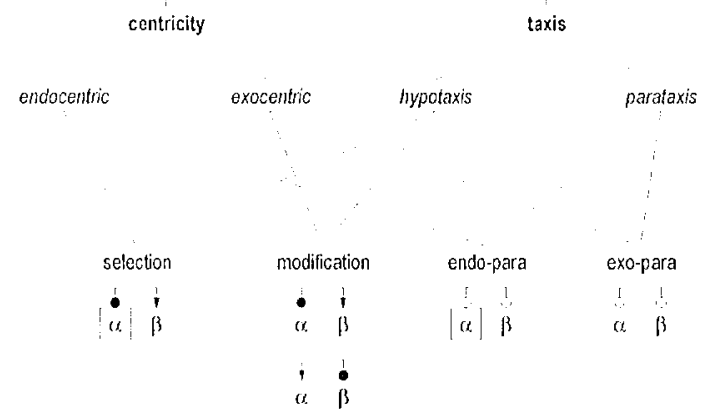

I lictarchy 4: Structural syntagmatics

Due to the fact that there always is a principal or leading element in the endocentric relations, different linguistic theories typically agree on how to interpret these relations structurally. But there is no consensus - often even within the same linguistic theory - on the structural interpretation of the exocentric relations. So, additional factors are usually taken into consideration as supporting the introduction of particular conventions. The latter, however, are not always linguistically motivated, 
the choice is sometimes arbitrary and often due to theory-specific technical reasons.

\section{Combinatorial syntagmatics}

The combinatorial dimension in the proposed taxonomy (Hicrarchy 5) largely corresponds, in our understanding, to what [S\&L95] regard as morphological signalling of direct syntactic relations.

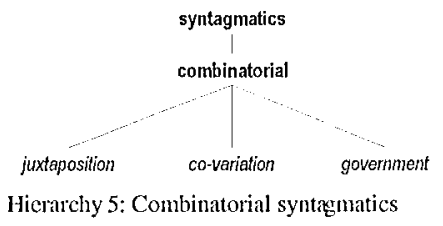

The combinatorial syntagmatic relation of juxtaposition presupposes no overt morphological indication. As to government, it is traditionally understood as the determination by one element of the inflectional form of the other, i.c. form government. Its classical instance is, of course, case government. In [Cann93] (p. 51) these morphosyntactic relation is formulated for some construction involving $\gamma$ and $\delta$ in the following way: $\gamma$ governs $\delta$ if (i) varying the inflectional form of $\delta$ while keeping $\gamma$ constant leads to ungrammaticality, and (ii) varying the form of $\gamma$ and keeping $\delta$ constant makes no difference to grammaticality. The systcmatic co-variation of linguistic forms is typically realised as feature congruity, i.e. compatibility of values of identical grammatical categorics of syntactically combined linguistic items. In our view, two general covariation types must be distinguished (cf. Hicrarchy 6), namcly, asymmetric and symmetric co-variation, with only the former actually corresponding to the traditional directional concept of agrecment, e.g., [Cor98].

\section{co-variation \\ asymmetric symmetric

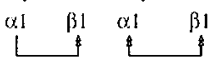 \\ $\alpha 1 \quad \beta 1$ \\ Hicrarchy 6: Morphosyntactic co-variation}

As the term suggests, the asymmetry of co-variation presupposes a controller-target configuration. This is to be contrasted with the symmetry of $\mathrm{co}^{-}$ variation which is not interpretable in these terms. Symmetric co-variation, in essence, would presume redundancy as if both co-varying syntactic items were controllers and targets at the same time.

\section{Endocentric hypotaxis (selection)}

The endocentric hypotaxis corresponds to the traditional notion of selection. Even though not directly observable, it underlies specific morphosyntactic realities interpreted in Hicrarchy 7 as resulting from a cross-classification with the combinatorial syntagmatic relation types.

The traditional notion of subcategorisation can thus be viewed as a selection that is realised via govern- ment. Two general options are usually available across languages for externalising the governed selection (i.c. subcategorisation) of nominal categorics in actual syntactic constructions.

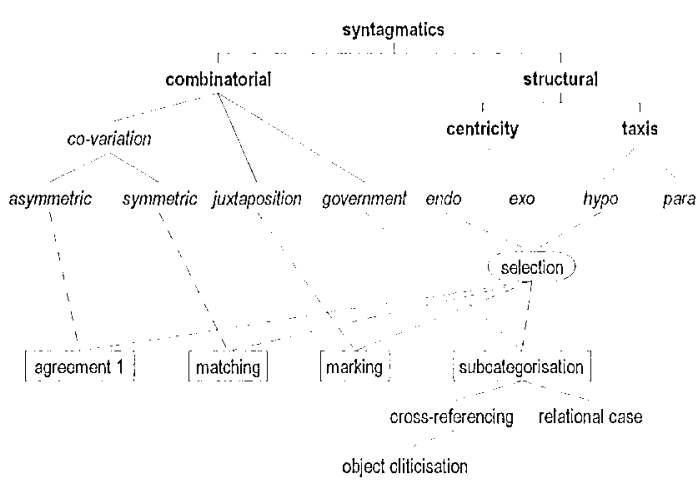

Hicrarchy 7: Selection

A typical definition of the first one can be found in [Blake94]: "Case in its most central manifestation is a system of marking dependent nouns for the type of relationship they bear to their heads". The relational case explicating case government stands in opposition to the so-called concordial case observed in case-governed modification environments and presented in Hicrarchy 8. The second option to externalise subcategorisation of nominal categories is the cross-referencing the syntactic function of the dependent at the head. It is actually confined to certain core grammatical relations and typically amounts to some kind of pronominal representation of these grammatical relations at the head. As [Blake94] observes, the cross-referencing pronominal clements serve as an alternative to case in signalling grammatical relations. In Slavic, there are two candidates for the second type of externalising a governed selection. On the one hand, the verb inflection can possibly be interpreted as crossreferencing the subject function, especially in Bulgarian where no relational case is realised on the dependent. On the other hand, pronominal clitics can cross-reference the direct and the indirect object in Bulgarian verb complex, cf. [Avg97a], as well as the possessor relation in Bulgarian noun phrases, $\mathrm{cf}$. [Avg97b]. Therefore, the systematic relation of object cliticisation can be viewed as a more specific instance of cross-referencing. In general, a nominal category representing a grammatical relation that is cross-referenced at the head selecting this nominal category need not be overtly realised. So, the crossreferenced noun phrase controlling the agreement can typically be omitted.

In our view, the systematic relation of marking (Hierarchy 7) is an instance of juxtaposed selection, i.e. an endocentric hypotaxis that is realised via juxtaposition. We promote a fairly extensive understanding of this syntactic relation as involving various functional categories, including auxiliaries, particles, determiners, prepositions, conjunctions, ctc. The notion of morphosyntactic marking is introduced in [Avg97a] for syntagmatic relations 
holding in Bulgarian analytic verb forms between the main verb as a syntactic (and semantic) head and the possibly multiple auxiliary verbs as markers specilying it. The agreement between the verb and its subject or complement is interpreted in our taxonomy as a selection realised via asymmetric co- variation (agreement $I$ ). It typically occurs in combination with the relation of subcategorisation (cf Table 1) which in languages employing relational case is realised as case assignment, while in those cmploying cross-referencing as a syntactic function identification.

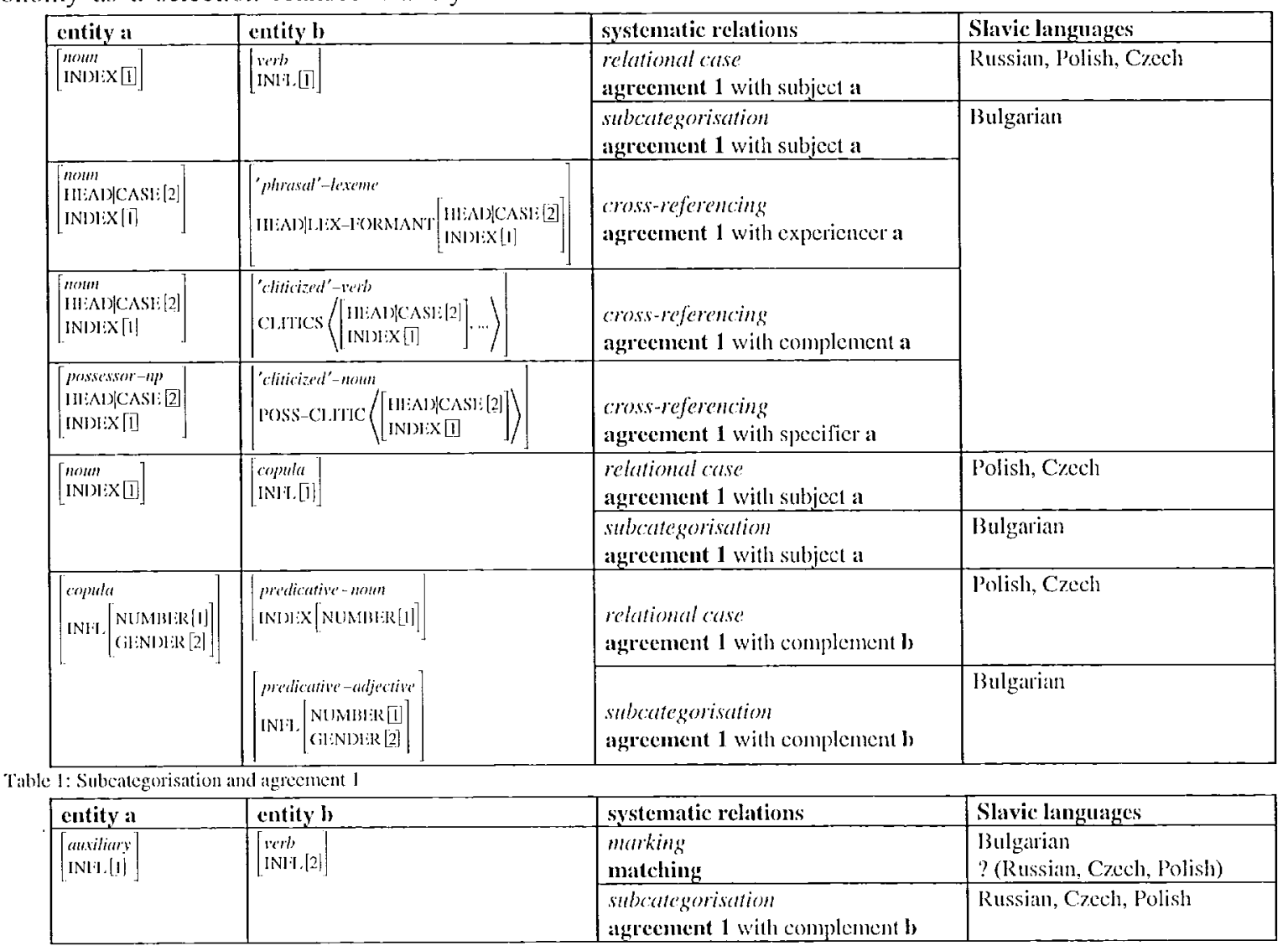

Table 2: Marking and matching

Finally, what we call matching corresponds to a selection realised via symmetric co-variation. Its most typical instance can be found where there is compatibility in person, number or gender between (possibly multiple) auxiliaries and a main verb. Matching usually co-occurs with a marking relation (cf. Table 2) which, as shown in Hicrarchy 7 , is interpreted as a juxtajosed selection.

\section{Exocentric hypotaxis (modification)}

The exocentric hypotaxis corresponds to the traditional notion of modification. It underlies specific morphosyntactic realities resulting from a crossclassification with combinatorial syntagmatic relation types (ef. Hierarchy 8). In all of them, we are confronted with a relation of subordination in which, however, there is no indisputable prominent element.

In general we assume that there is no "case agreement". Rather, the regular compatibility of case specifications between the involved syntactic items is due to a modification relation realised in a governed environment. In other words, we can regard concordial case as a typical instance of a governed modification. The asymmetric co-variation realising a modification relation can be called concord, but let us refer to it - for the sake of simplicity - as agreement 2 . In the majority of Slavic languages, but obviously not in Bulgarian, this relation occurs in combination with concordial case (cf. Table 3). Note that in our approach the treatment of nominal apposition would be parallel to that of the adjectivenoun relations.

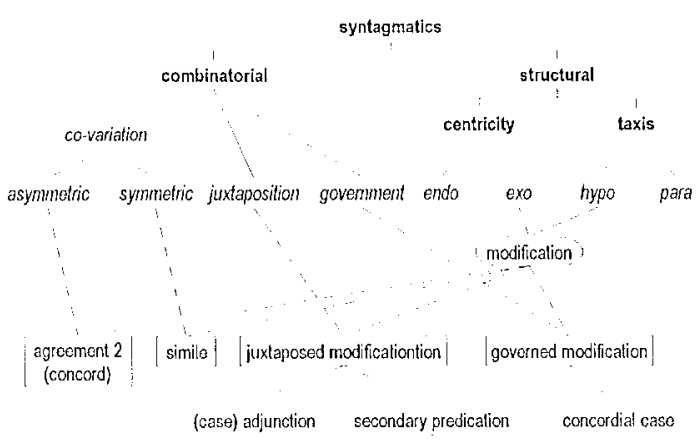

predicative case acjunction

Hicrarchy 8: Modification

The main difference between the agreement I (Hicarchy 7) and the agreement 2 (or concord) discussed here amounts to the fact that these covariation relations exhibit different centricity. Cross-classifying exocentric hypotaxis with symmetric co-variation results in what can be called simile and is typically observed in comparative 
constructions, provided appropriatc categories are available. This systematic relation differs from that of parallelism (distinguished in Hicrarchy 10) in being hypotactic in nature, and thus, an actual instance of modification. Similarly to the asymmetric agreement 2 (concord), the simile relation co-occurs with concordial case, ef. ex. 6 . The systematic relation of (case) adjunction is an instance of juxtaposed modification.

\begin{tabular}{|c|c|c|c|}
\hline entity a & entity l) & systematic relations & Slavic languages \\
\hline \multirow[t]{2}{*}{$\left.\begin{array}{l}\text { adjective } \\
\text { INI:L }\left[\begin{array}{l}\text { CASE: }[1] \\
\text { NUMHII: }[2] \\
\text { GIINI)I:R } 3\end{array}\right]\end{array}\right]$} & \multirow[t]{2}{*}{ 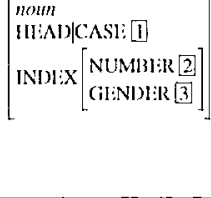 } & $\begin{array}{l}\text { concordial case } \\
\text { agreement } 2 \text { (concord) }\end{array}$ & Russian, Polish, Czecli \\
\hline & & $\begin{array}{l}\text { governed modification } \\
\text { agreement } 2 \text { (concord) }\end{array}$ & Bulgarian \\
\hline \multirow[t]{2}{*}{$\begin{array}{l}\text { nown } \\
\text { HI:AD)(CASI: I } \\
\text { INII:X[NUMBI:R [2]] }\end{array}$} & \multirow[t]{2}{*}[\begin{array}{l}{\text{noton}}\\
{\text{INIIIXX[NUMBIIR[2]}]}\end{array}]{} & $\begin{array}{l}\text { concordial case } \\
\text { agreement } 2 \text { (concord) }\end{array}$ & Russian, Polish, Czech \\
\hline & & $\begin{array}{l}\text { govemed modification } \\
\text { agreement } 2 \text { (concord) }\end{array}$ & Bulgarian \\
\hline
\end{tabular}

Table 3: Concordial case and agreenent 2 (concord)

Interestingly, the well-known "instrumental" problem - i.c. whether we are confronted with a complement or a free adjunct - narrows down in our approach to a fluctuation between adjunction (juxtaposed modification - Hicrarchy 8) and subcategorisation (governed sclection - Hicrarchy 7), with the crucial point being merely a different centricity interpretation. Also the secondary predication (referring, typically, to the relation holding between a verb and a secondary controlled predicative) is a subtype of juxtaposed modification, with the predicative case adjunction as a more specific instance. As to the relation holding between the secondary predicative and the subject or the object, it is an instance of control and presupposes coreference. The latter two concepts realise an endocentric parataxis and are introduced in Hicrarchy 9.

\section{Endocentric parataxis}

In the endocentric parataxis there is a prominent itcm but no subordination relation. This allows us to model concepts like co-reference, correlation, comarking (illustrated by ex. 6) and control as naturally resulting from a cross-classification with the combinatorial syntagmatic relation types.

If an endocentric parataxis is revealed by an asymmetric co-variation, this results in co-reference. This systematic relation is found in relativisation (i.e. between a nominal category and the relative pronoun introducing a relative clause that modifies this nominal category), in resumption (i.e. between a nominal category and the pronominal element resuming it in a different syntactic domain), and in binding (i.e. between a pronoun and its antecedent). When, however, an endocentric parataxis is revealed in a symmetric co-variation, we can speak of correlation. But in both instances of co-variation, we are confronted with pairing indices (or restricted parameters) of referential objects. What we propose to distinguish as co-marking corresponds to endocentric parataxis that is realised via juxtaposition. So, it contrasts with the systematic relation of marking (presented in Hierarchy 7) only along the taxis dimension of structural syntagmatics inasmuch as there is no subordination relation between the involved syntactic items. As to the systematic relation of syntactic control, it is registered in our taxonomy as an endocentric parataxis resulting in a form government. In Bulgarian, it co-occurs with co-reference - ex. 3 and ex. 4 .

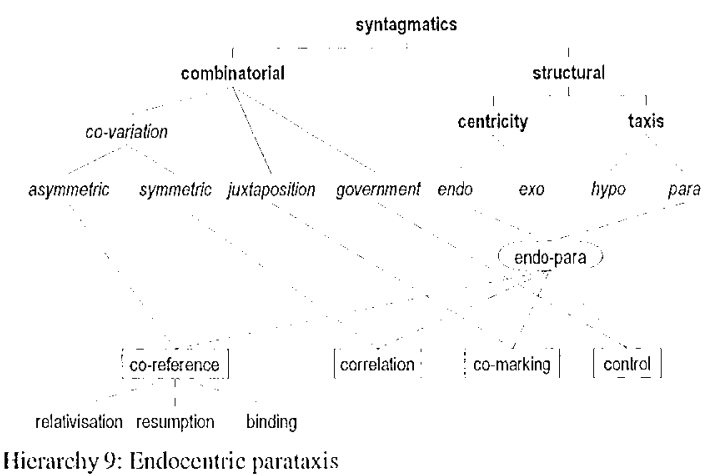

Exocentric parataxis

The exocentric parataxis is the actual unmarked case: there is neither a prominent element nor a subordination relation between the involved syntactic items. A cross-classification with combinatorial syntagmatic relation types allows us to encode further phenomena that are shown Hierarchy 10.

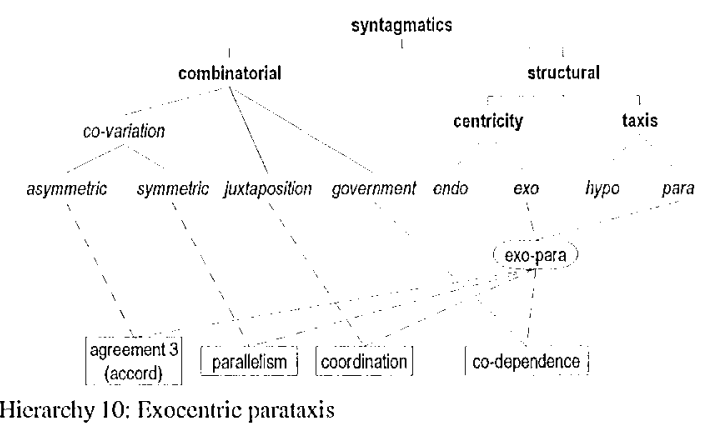

The relation of co-dependence plays a crucial role in a number of constructions. It is an exocentric parataxis that is realised via government, with a special requirement that all involved syntactic items have the same governor. In other words, these items are typically dependents of the same syntactic head. What we call agreement 3 (or accord) corresponds to an exocentric parataxis that is realised via asymmetric co-variation. It regularly presupposes a co- 
dependence relation (ef. Table 4), and its most typical instance can be found as a compatibility in number or gender between the subject and the predicative in copular constructions. Another instance is the co-dependence relation holding between a dependent of the primary predicate (i.e. the verb) and a secondary predicative in ex. 1 and ex. 2 .
When exocentric parataxis is externalised by a symmetric co-variation, we are confronted with parallelism. It co-occurs in ex. 5 with codependence.

The coordination relation is generally interpretable as an exocentric paratactic juxtaposition.

\begin{tabular}{|c|c|c|c|}
\hline entity a & entity b & systematic relations & Slavic languages \\
\hline$\left[\begin{array}{l}\text { Inomm } \\
\text { INDI: }\end{array}\left[\begin{array}{l}\text { NUMIII: }[1] \\
\text { Gi:NIII: }[2]\end{array}\right]\right.$ & 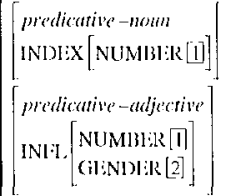 & $\begin{array}{l}\text { co-dependence } \\
\text { agreement } \mathbf{3} \text { (accord) between subject a and } \\
\text { complement b }\end{array}$ & $\begin{array}{l}\text { (Russian ?), Bulgarian, } \\
\text { Polish, Czech }\end{array}$ \\
\hline 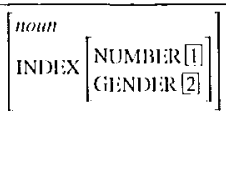 & 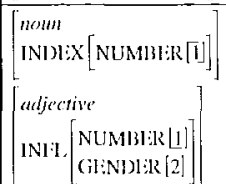 & $\begin{array}{l}\text { co-dependence } \\
\text { angreement } 3 \text { (accord) between subject / } \\
\text { object a and secondary predicative b) }\end{array}$ & $\begin{array}{l}\text { Russian, Bulgarian, Polish, } \\
\text { Crecls }\end{array}$ \\
\hline
\end{tabular}

\section{Conclusion and prospects}

We have presented an approach of computational grammar design that supports the notion of grammar sharing and, moreover, lends itself to the formal linguistic description of individual languages as well as language families. The basic building blocks of such a grammar were demonstrated with the example of Slavic languages. Grammars of this type can straightiorwardly be extended and employed in a number of development and runtime systems accommodating HPSG. Some of these systems have reached a parsing efficiency that makes them suited for a variety of applications, [IOOTU20(0)|. Although the original motivation for the work came from applied research, the insights that were gained on the differences between Slavic languages, led to new results in comparative linguistic description. We expect that psycholinguistic rescarch on bilingualism and second language acquisition will greatly benefit from opportunities of modelling shared grammatical knowledge. The insights gained by such models will in turn be uselul for $\mathrm{CALL}$ applications and for the computational treatment of cross-language interference in grammar and style checking.

\section{References}

[ASU99] Avgustinova, T., W. Skut and H. Uszkoreit. Typological similarities in HPSG: a calse study on Slavic verb diathesis. In Przepiórkowski, $\Lambda$. and R. Borsley (ed.) Slavic in IHPSG. CSLI 1999: 1-28
[Avg97a] Avgustinova, T. Word order and clitics in Bulgarian. Saarbriicken Disserlations in Computational Linguistics and Language Technology, Volume 5, 1997

[Avg97b] Avgustinova, T. Clustering clities in Bulgarian nomimal constituents. In: Proceedings of IDSSL-2, Potsdam 1997

[BOP88] Bemová, A., K. Olival and J. Panevoví. Some probfems of machine translation between closely related languages. In: P'roceedings of COLJNG'88, 13udapest 1988

[Blake94] Blake, B.J. Case. Cambridge Texubooks in Linguislics. Cambridge University Press, 1994

[Cann93] Cann, R. P'atterns of headedness In: Corbett, G., N. linaser and S. MeGlashan (ed.) Ileads in grammatical theory. Cambridge University Press, 1993. 44-72

[Cor98] Corbet, G. Agreement in Slavic. Position paper for the workshop "Comparative Slavic Morphosyntax: The State of the Art", Indiama University, 1998

[FOTU2000] lilickinger, D., S. Oepen, J. Tsujii, and H. Uszkoreil (ed.).(in press) Journal of Natural l anguage Engineering. Special lssue on leflicient Processing with HI'SG. Volume 6 (1). Cinbridge, UK: Cambridge University l'ress, 2000.

[GLJ'R97] Gamon, M., .C. Lozano, J. l'inkham and T. Reutter. Practical experience with grammar sharing in multilingual NIP. Technical report MSR-'TR-97-16, Redmond 1997

[Kam88] Kameyama, M. Atomization in grammar sharing. In: Procecdings of 26th Amnal Meeting of ACL, New York 1988

[Pin96] P'inkham, J. Grammat Sharing in French and linglish. In: Proceedings of IANLP' 1996

[S\&]95] Schmidt, P', and W. Lchfeldt. Kongruenz - Rektion Adjunktion. Systematische und historische Untersuchungen zur allgemeinen Morphosyntax und zu den Wortfügungen (slovosočetanija) im Russischen. Specimina Philologiac Slavicac. München: Oto Sagner 1995

\section{Sample analyses (relational charts)}

ex. 1 (Russian) 'She turned out a healtlyy girl.'

\begin{tabular}{|c|c|c|c|}
\hline $\begin{array}{c}\text { Ona } \\
\text { 3SG.F.NOM }\end{array}$ & $\begin{array}{l}\text { relational case [NOM] } \\
\text { agrecment } 1 \text { [SG.F] }\end{array}$ & & $\begin{array}{l}\text { co-dependence } \\
\text { agreement } 3 \text { (accord) [SG.F] }\end{array}$ \\
\hline & $\begin{array}{l}\text { okazalas' } \\
\text { turned-SGi.I: }\end{array}$ & & $\begin{array}{l}\text { relational case [INST] } \\
\text { agreement } 1 \text { [SG.F] }\end{array}$ \\
\hline & & $\begin{array}{c}\text { zdorovoj } \\
\text { healthy-SG.1.INSI }\end{array}$ & $\begin{array}{l}\text { concordial case [INST] } \\
\text { agrcement } 2 \text { (concord) [SG.li] }\end{array}$ \\
\hline & & & $\begin{array}{c}\text { devočkoj. } \\
\text { girl-SG.F.JNST }\end{array}$ \\
\hline
\end{tabular}


ex. 2 (Russian) "lhey ordered him to come washed.'

\begin{tabular}{|c|c|c|c|c|}
\hline $\begin{array}{c}\text { Oni } \\
\text { 3PI.NOM }\end{array}$ & $\begin{array}{l}\text { relational case [NoM] } \\
\text { agreement } 1 \text { [PL] }\end{array}$ & & $(\cdots)$ & \\
\hline & $\begin{array}{c}\text { veleli } \\
\text { ordered-PL }\end{array}$ & relational casc [DAT] & subcategorisation [INF'] & \\
\hline & & $\begin{array}{c}\text { chil } \\
\text { 3SG.M.DAT }\end{array}$ & control & $\begin{array}{l}\text { co-dependence } \\
\text { agrecment } 3 \text { (accord) [SG.M] }\end{array}$ \\
\hline & & & $\begin{array}{c}\text { prijti } \\
\text { conc-INF }\end{array}$ & predicative case adjunction [INST] \\
\hline & & & & $\begin{array}{c}\text { umytym. } \\
\text { washed-SG.M.INST }\end{array}$ \\
\hline
\end{tabular}

ex. 3 (l3ulgarian) 'John saw Mary ill (reportedly).'

\begin{tabular}{|c|c|c|c|c|}
\hline \multirow[t]{5}{*}{$\begin{array}{c}\text { Ivant } \\
\text { Ivan-3SG.M } \\
\end{array}$} & & $\begin{array}{l}\text { subealcgorisation } \\
\text { agreement } 1 \text { [3SC ( } . M]\end{array}$ & & \\
\hline & $\begin{array}{c}j a \\
\text { ACC.SG.l }\end{array}$ & object cliticisation & $\begin{array}{l}\text { cross-refercncing } \\
\text { agreement } 1 \text { [3SG.F] }\end{array}$ & $\begin{array}{l}\text { control } \\
\text { co-reference [SG.F] }\end{array}$ \\
\hline & & $\begin{array}{c}\text { vidjal } \\
\text { saw-3SG.M }\end{array}$ & subcategorisation & sccondary predication \\
\hline & & & $\begin{array}{c}\text { Maria } \\
\text { Mary-SG.F }\end{array}$ & $\begin{array}{l}\text { control } \\
\text { co-reference [SG.I] }\end{array}$ \\
\hline & & & & $\begin{array}{l}\text { bolna. } \\
\text { ill-SG.F }\end{array}$ \\
\hline
\end{tabular}

ex. 4 (Bulgarian) 'You would come disguised (reportedly).'

\begin{tabular}{|c|c|c|c|c|c|}
\hline $\begin{array}{c}T i \\
2 \mathrm{SG}\end{array}$ & & $\therefore$ & $\because \Rightarrow$ & $\begin{array}{l}\text { subcategorisation } \\
\text { agreement } 1 \text { [2S(i] }\end{array}$ & $\begin{array}{l}\text { cotitiol } \\
\text { co-reference [SC] }\end{array}$ \\
\hline & $\begin{array}{c}s i \\
\Lambda U X .2 S G \\
\end{array}$ & $\begin{array}{l}\text { marking } \\
\text { matching [2SG.F] }\end{array}$ & & $\begin{array}{l}\text { marking } \\
\text { matching [2SG.F] }\end{array}$ & $\begin{array}{l}\text { control } \\
\text { co-reference }[S(\mathrm{i} . \mathrm{l}]\end{array}$ \\
\hline & & $\begin{array}{c}\text { štjala } \\
\text { AUX-SG.F }\end{array}$ & & & \\
\hline & & & $\begin{array}{c}\text { da } \\
\text { particle }\end{array}$ & narking & \\
\hline & & & & $\begin{array}{l}\text { dojdeš } \\
\text { come-2sG }\end{array}$ & secondary predication \\
\hline & & & & & $\begin{array}{l}\text { maskirama. } \\
\text { disguised-sC.: }\end{array}$ \\
\hline
\end{tabular}

ex. 5 ('olish) 'l consider him 10 be nice ito be a fool.'

\begin{tabular}{|c|c|c|c|}
\hline $\begin{array}{c}\boldsymbol{W} \boldsymbol{a}+a m \\
\text { consider-1SG }\end{array}$ & relational case $[\triangle \mathrm{CC}]$ & & relational case fprepositional $\Lambda \mathrm{CC}$ \\
\hline \multirow[t]{3}{*}{ 、 } & $\begin{array}{c}g 0 \\
\text { 3SG.M.ACC }\end{array}$ & & $\begin{array}{l}\text { co-dependence } \\
\text { parallelism [SG.M / 3SG.M] }\end{array}$ \\
\hline & & $\begin{array}{l}z a t \\
\text { for } \\
\end{array}$ & marking \\
\hline & & & $\begin{array}{l}\text { milego / durnia. } \\
\text { nice-SG.M.ACC / fool-3SG.M.ACC }\end{array}$ \\
\hline
\end{tabular}

ex. 6 (Russian) 'l suffered for him as for a sou,'

\begin{tabular}{|c|c|c|c|c|c|c|}
\hline $\begin{array}{c}J a \\
1 \mathrm{SG} \\
\end{array}$ & $\begin{array}{l}\text { relational case [NOM] } \\
\text { agrecment } 1[\mathrm{SG}]\end{array}$ & & & & & \\
\hline & $\begin{array}{c}\text { stradala } \\
\text { suffered-SG.F }\end{array}$ & & relational case [prepositional ACC] & adjunction & & \\
\hline & & $\begin{array}{l}z a \\
\text { for }\end{array}$ & marking & & co-marking & \\
\hline & & & $\begin{array}{c}\text { nego } \\
\text { 3SG.M.ACC }\end{array}$ & & & $\begin{array}{l}\text { concordial case }[A C C] \\
\text { simile } \mid 3 \mathrm{~S} \text { ( } i . \mathrm{M}]\end{array}$ \\
\hline & & & & $\begin{array}{c}k a k \\
\text { as }\end{array}$ & & marking \\
\hline & & & & & $\begin{array}{l}z a \\
\text { for }\end{array}$ & \\
\hline & & & & & & $\begin{array}{c}\text { syna } \\
\text { Son-3SG.M.ACC }\end{array}$ \\
\hline
\end{tabular}

